\title{
Probability of Low Temperature Stress at Different Growth Stages of Boro Rice
}

\author{
M S Kabir ${ }^{1}$, M Howlader², J K Biswas ${ }^{3}$, M A A Mahbub ${ }^{4}$ and M Nur-E-Elahi ${ }^{5}$
}

\begin{abstract}
The most sensitive stages of Boro rice against the low temperature are agronomic panicle initiation (API), reduction division (RD) and flowering/anthesis. The critical low temperature is growth stage specific. The time and intensity of the critical low temperature during Boro season has a direct impact on the growth and yield of a crop. Therefore, it is necessary to understand the probability of the critical low temperature with respect to the growth stages to have a good planning for safe harvest. Long term weekly low temperature data have been used to estimate the probability of falling low temperature on those stages and the return period was computed. The growth durations of 1- and 30- November seeded Boro rice crop from 45-day-old seedling of BRRI dhan28 (short duration) and BRRI dhan29 (long duration) are considered to observe the probability. A Boro crop encountering critical low temperature is appeared to suffer from cool injury. The extent of cool injury depends on the nature and duration of low temperature and diurnal change of low (night) and high (day) temperature. The critical low temperature for a rice crop at API, RD and anthesis are 18,19 and $22^{\circ} \mathrm{C}$, respectively. Boro rice is grown between November and May. The low temperature occurs from October to early March. There is, therefore, the probability of low temperature occurrence from the crop establishment to the flowering stage is a great concern. The probability of experiencing stage-wise critical temperature approaches to $100 \%$ for early established and short duration crop. However, the late established and long duration crop has the probability little less than the early and short duration crop. In a study it has been observed that short duration BRRI dhan 28 having $64.6 \%$ sterility to yield $2.5 \mathrm{t}$ ha-1 and BRRI dhan $29,40.8 \%$ sterility to yield $6.5 \mathrm{t}$ ha-1. The percentages of corresponding sterility for late established crops were 35.9 and $32.8 \%$. Irrespective of growth duration, the yield is affected a little of the late established crop. Despite low temperature along with the reproductive phase, the late established crop is quite safe due to the parallel high (day) temperature $\left(31-35^{\circ} \mathrm{C}\right)$. The high maximum temperature appears to play an important role through the alleviating effect of low temperature. But for early-established particularly short duration variety could not escape the low temperature at some of its sensitive growth stages as the high temperature appears to stay a several degree low $\left(27-29^{\circ} \mathrm{C}\right)$ at that time. The low level of high temperature is appeared to drag down the low temperature to aggravate the growth and development of a crop. Therefore, not only the variation of high temperature of the day but also the variation of critical low temperature might have some role in alleviating effect of cool-injury. The periodic return of critical low temperature $\left(10-15^{\circ} \mathrm{C}\right)$ during the reproductive stage may occur every year or every alternate year depending on the time across the cropping season and the region as well. Therefore, the critical low temperature, the high temperature during the low temperature period, periodic return of the critical low temperature with respect to growing region and concerned factors should be a consideration for planning a Boro crop.
\end{abstract}

\section{INTRODUCTION}

Extreme temperatures either low or high are destructive to plant growth and development. The critically low and high temperatures, normally below $20^{\circ} \mathrm{C}$ and above $30^{\circ} \mathrm{C}$ vary from one growth stage to another. These critical temperatures vary with the genotype, duration of critical temperature, diurnal changes and physiological status of the plant, Yoshida (1981). The probability of experiencing critical temperature for a particular rice crop also varies with the crop growing season, crop establishment schedule and agronomic practices also. In Bangladesh, sterility due to critical low temperature in Boro rice (irrigated rice generally grown from November to May) is getting importance in the recent years. Boro rice might suffer from extreme temperature particularly low temperature at the reproductive stage of the crop. Even low temperature at the crop establishment and tiller development stage (vegetative phase) of the crop might affect the growth and development of the crop. The most sensitive stages against the stresses are API (24 days before heading), RD (12-14 days before heading) and anthesis (0 days before heading), Hoshikawa (1975); Yoshida (1981).

The cool-injury symptom differs from a growth stage to another. Poor panicle exsertion, delayed heading, spikelet degeneration at the reproductive stage might yield complete sterility.

1Director (Administration and Common Service), ${ }^{2}$ Former Chief Scientific Officer and Head, Agricultural Statistics Division; ${ }^{3}$ Director General, ${ }^{4}$ Former Scientific Officer, Plant Physiology Division and 5Former Director General, Bangladesh Rice Research Institute (BRRI), Gazipur 1701. *Corresponding author's E-mail: kabir.stat@gmail.com 
Low temperature at the transplanting affects root growth and poor leaf development leading to poor crop establishment. The low temperature at the early growth stages affects natural nutrient uptake and metabolic activities leading to poor vegetative growth reflected as yellowing leaves, stunt growth and reduced tiller number, Nishiyama (1995). Bangladesh Rice Research Institute recommends seeding of short and long duration crop on 15 November30 November and 5 November-25 November, respectively. But farmers in some of the intensive Boro areas (haor area) might not follow the prescribed schedule due to early recession of flood water as they have to utilize residual flood water for the seedling raising and initial crop establishment practice. Generally a short duration BRRI variety is recommended in a haor area to avoid the flash flood during late April to Early May. Early seeding of a short duration variety on seed bed (late October to early November) might experience low temperature at any growth stage. Even a long duration, direct seeded crop may succumb to cool injury at its reproductive stage, Biswaset al. (2008). The time and intensity of low temperature during Boro season have direct impact on the growth and yield of a crop. This study examines the probabilities of critical low temperature and its effect on different growth stages and their pattern of periodic return with respect to few regions of intensive Boro area.

\section{MATERIALS AND METHODS}

Weekly average of daily minimum temperature data of 33 (1975-2007) years for Gazipur (favourable), 57 (1950-2006) years for Dinajpur (Boro-intensive northern cold belt) and Mymensingh (includes Boro intensive Kishoreganjhaor area) are used in this study (Data source: BRRI and Bangladesh Meteorological department: BMD). For the simplicity only three regions were considered. Pearson Type I distribution was applied to graduate probability distribution of weekly minimum temperature of each district. The probability density function (pdf) of Pearson Type I distribution is given by

$$
\begin{aligned}
& f(x)=\frac{1}{(b-a)^{m_{1}+m_{2}+1} B\left(m_{1}+1, m_{2}+1\right)}(x-a)^{m_{1}}(b-x)^{m_{2}}, \\
& a \leq X \leq b ; m_{1}, m_{2}>0 \\
& \text { where, } x \text { is the value of minimum }
\end{aligned}
$$
temperature; $B$ is the Beta function; $a, b, m_{1}$ and $\mathrm{m}_{2}$ are estimated from the above function using minimum temperature value.

A computer programme written in SAS language $(\mathrm{MH}, 2007)$ was used to estimate the expected weekly low temperature at different probability (5-95\%) levels. The probability curves were fitted using Excel 2000. The return period or recurrence interval $(\mathrm{T})$ was computed by

$$
\mathrm{T}=\frac{1}{\mathrm{~F}},
$$

where $\mathrm{F}$ is the cumulative probability.

Two crop establishment schedules were used, one at 1 November (early established) and another at 30 November (late established). Forty-five-day-old seedlings were considered for the study. The growth stages of the BRRI dhan28 (short duration) and BRRI dhan29 (long duration) were estimated as per Gomostaet al. (2001). The crop establishment of both long and short duration variety was considered at the same time. The critical low temperatures with respect to growth stages were used as per Yoshida (1981).

\section{RESULTS AND DISCUSSION}

\section{Results}

Early established (1-November seeded) crop: The active root and tiller development of 1Novemberseeded 45-day-old seedling take place in between late December to late January (Fig 1). 

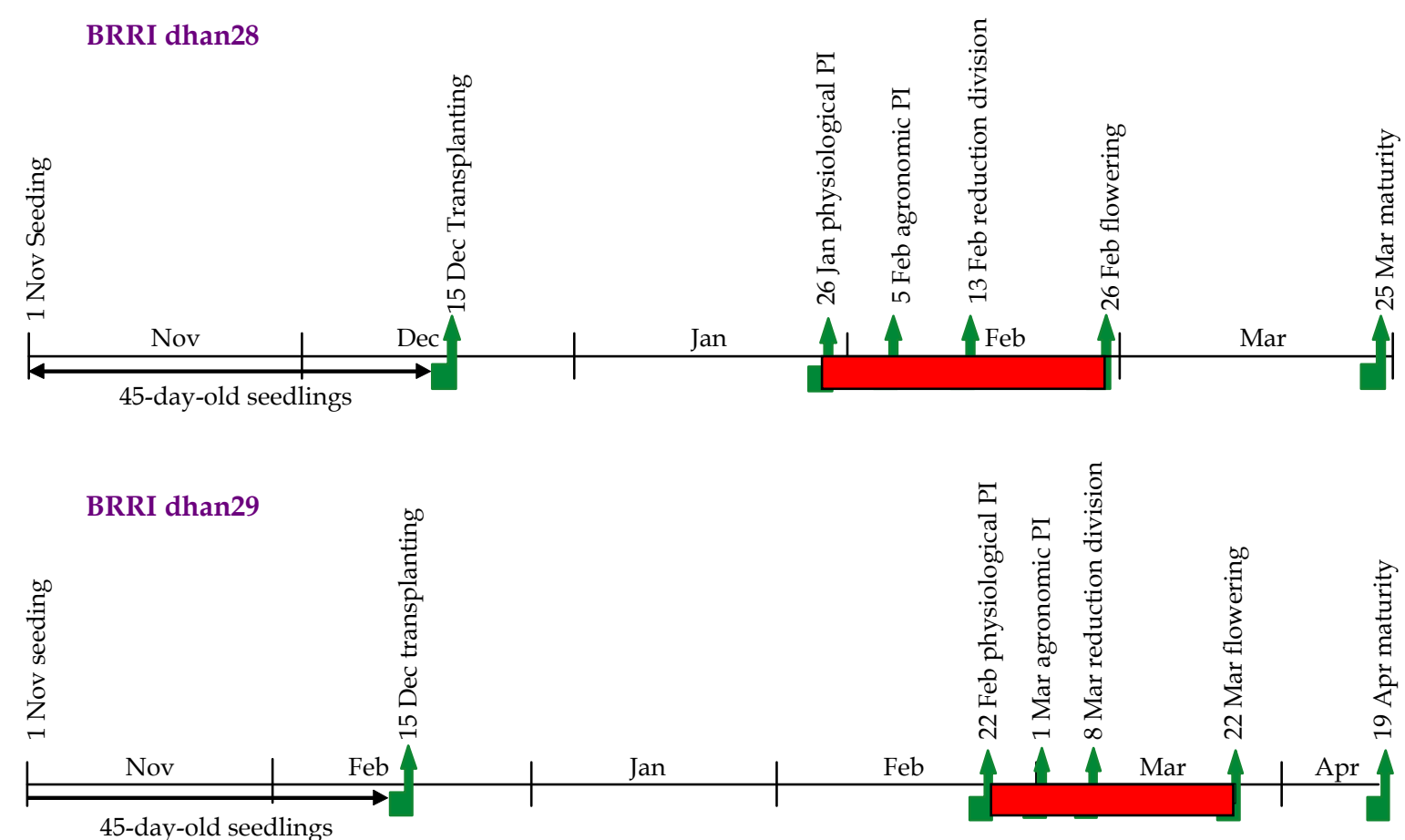

Fig. 1. Life cycle of BRRI dhan28, when seeded on 1 November (Growth duration 145 days) and BRRI dhan29, when seeded on 1 November (Growth duration 170 days).

The most sensitive API, RD and flowering/anthesis are appeared to occur on 5 February, 13 February and 26 February respectively for short duration BRRI dhan28. For long duration BRRI dhan29, these dates are 1 March, 8 March and 22 March. Asthe short and long duration crops are considered to establish at the same time, they have to experience more or less similar low temperature at the crop establishment. The probability of falling critical low temperature at the crop establishment at Gazipur, Dinajpur and Mymensingh are $74 \%, 100 \%$ and $80 \%$, respectively (Table 1 and Fig. 3).
The probability of the onset of low critical temperature is varied from panicle initiation stage and onward. For API, BRRI dhan 28 has the probability of $100 \%$ for all the regions considered here but for BRRI dhan29 the probabilities vary from $88 \%$ at Dinajpur to $100 \%$ at Gazipur and Mymensingh. Irrespective of growth duration and region, the RD and anthesis stage have $100 \%$ probability. The ripening stage of BRRI dhan29 has less probability of critical low temperature than that of BRRI dhan28. The probabilities at the ripening stage for BRRI dhan29 at Gazipur, Dinajpur and Mymensingh are 15\%, 17\% and $14 \%$, respectively whereas these values for BRRI dhan 28 are $44 \%, 81 \%$ and $60 \%$, respectively. 
Table 1. Probability of falling growth stage-wise critical minimum temperature for 1- November seeding

\begin{tabular}{l|c|c|c|c|c|c|c}
\hline \multirow{2}{*}{ Growth stage } & \multirow{2}{*}{$\begin{array}{c}\text { Critical low } \\
\text { temp }\left({ }^{\circ} \mathrm{C}\right)\end{array}$} & \multicolumn{3}{|c|}{ Probability of falling growth stages at critical temp. } \\
\cline { 3 - 8 } & & \multicolumn{2}{|c|}{ Gazipur } & \multicolumn{2}{c}{ Mymensingh } & \multicolumn{2}{c}{ Dinajpur } \\
\cline { 3 - 8 } & & $\begin{array}{c}\text { BRRI } \\
\text { dhan28 }\end{array}$ & $\begin{array}{c}\text { BRRI } \\
\text { dhan29 }\end{array}$ & $\begin{array}{c}\text { BRRI } \\
\text { dhan28 }\end{array}$ & $\begin{array}{c}\text { BRRI } \\
\text { dhan29 }\end{array}$ & $\begin{array}{c}\text { BRRI } \\
\text { dhan28 }\end{array}$ & $\begin{array}{c}\text { BRRI } \\
\text { dhan29 }\end{array}$ \\
\hline Germination & 10 & 0 & 0 & 0 & 0 & 0 & 0 \\
$\begin{array}{l}\text { Seedling establishment } \\
\text { transplanting) }\end{array}$ & 13 & 74 & 74 & 80 & 80 & 100 & 100 \\
Physiological PI & 15 & 100 & 67 & 100 & 70 & 100 & 87 \\
Agronomic PI & 18 & 100 & 100 & 100 & 100 & 100 & 88 \\
Reduction division & 19 & 100 & 100 & 100 & 100 & 100 & 100 \\
Flowering/Anthesis & 22 & 100 & 100 & 100 & 100 & 100 & 100 \\
Ripening & 18 & 44 & 15 & 60 & 14 & 81 & 17 \\
\hline
\end{tabular}

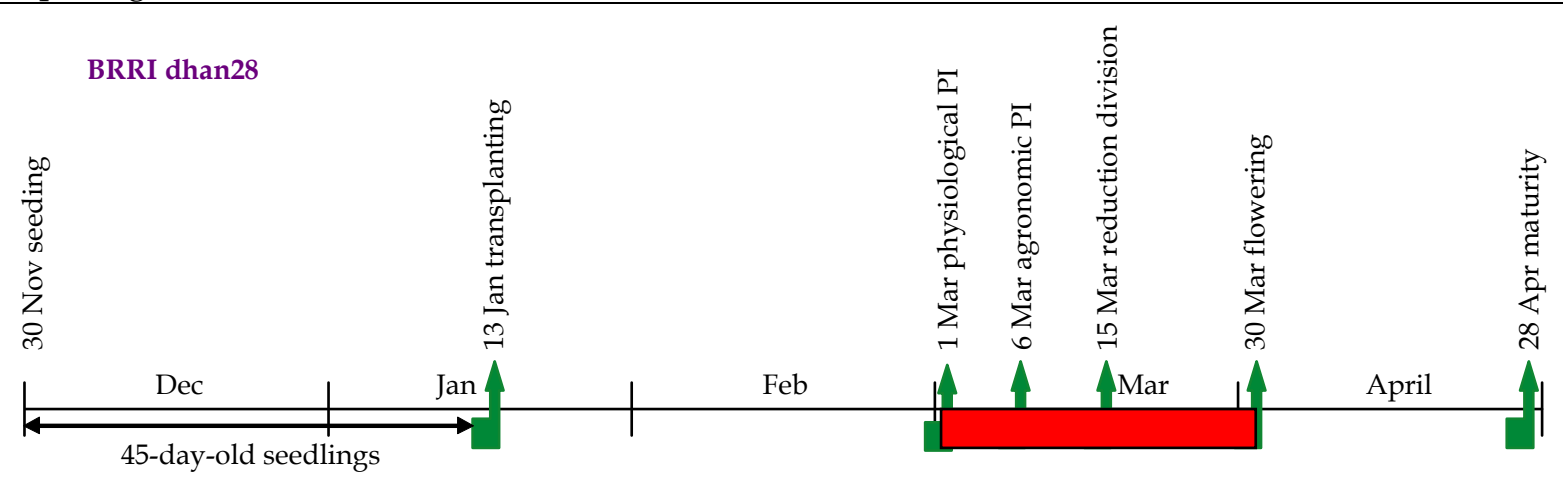

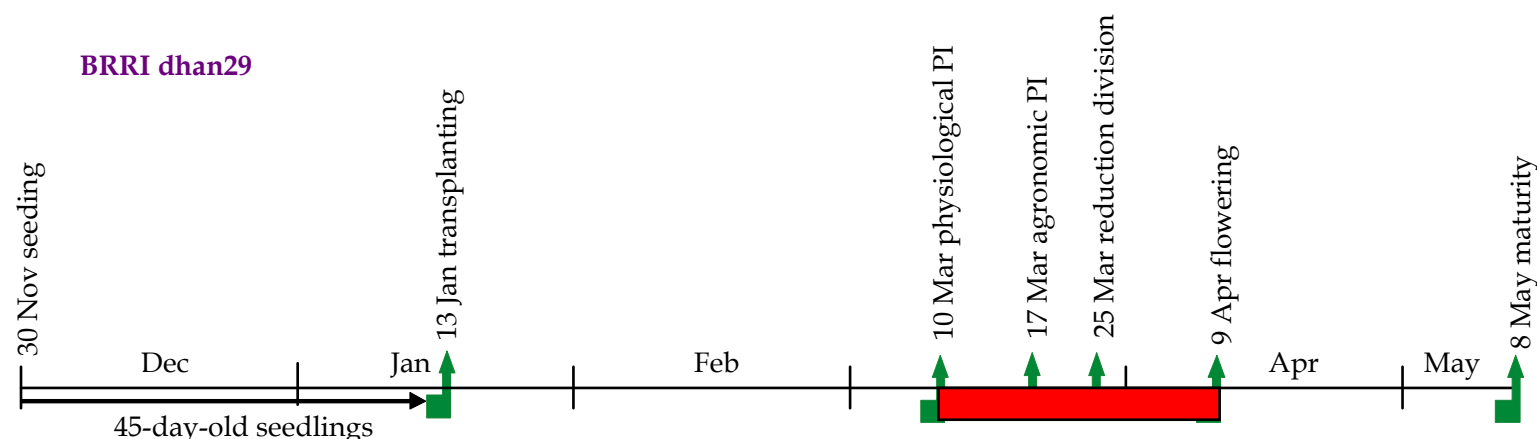

Fig. 2. Life cycle of BRRI dhan28, when seeded on 30 November (Growth duration 150 days) and BRRI dhan29, when seeded on 30 November (Growth duration 160 days).

Late established (30-November seeded) crop:

Theactive root and tiller development of these crops occurduring late January to late February (Fig. 2).

The subsequent growth stages, API, RD and flowering/anthesis for short duration variety are appeared to occur on 6, 15 and 30 March, respectively. The corresponding dates for long duration variety are 17 March, 25 March and 9 April. Irrespective of regions and growth durations the probability of critical low temperature during crop establishment is 100\% (Table 2 and Fig. 3).

Dinajpur has $100 \%$ probability of critical low temperature at the API stage for both BRRI dhan 28 and BRRI dhan29. The probabilities for BRRI dhan29 are comparatively less, which are $52 \%$ and $74 \%$ for Gazipur and Mymensingh, respectively. At $\mathrm{RD}$ and flowering/anthesis, the onset of probability pattern is more or less the same as that of API stage. 
Table 2. Probability of falling growth stage-wise critical minimum temperature for $\mathbf{3 0}$ November seeding

\begin{tabular}{|c|c|c|c|c|c|c|c|}
\hline \multirow{3}{*}{ Growth stage } & \multirow{3}{*}{$\begin{array}{l}\text { Critical low } \\
\text { temp }\left({ }^{\circ} \mathrm{C}\right)\end{array}$} & \multicolumn{6}{|c|}{ Probability of falling growth stages at critical temp. } \\
\hline & & \multicolumn{3}{|c|}{ Gazipur } & \multirow{2}{*}{$\begin{array}{c}\text { Mymensingh } \\
\text { BRRI } \\
\text { dhan29 }\end{array}$} & \multicolumn{2}{|c|}{ Dinajpur } \\
\hline & & $\begin{array}{c}\text { BRRI } \\
\text { dhan28 }\end{array}$ & $\begin{array}{c}\text { BRRI } \\
\text { dhan29 }\end{array}$ & $\begin{array}{c}\text { BRRI } \\
\text { dhan28 }\end{array}$ & & $\begin{array}{c}\text { BRRI } \\
\text { dhan28 }\end{array}$ & $\begin{array}{c}\text { BRRI } \\
\text { dhan29 }\end{array}$ \\
\hline Germination & 10 & 0 & 0 & 0 & 0 & 0 & 0 \\
\hline $\begin{array}{l}\text { Seedling establishment } \\
\text { (transplanting) }\end{array}$ & 13 & 100 & 100 & 100 & 100 & 100 & 100 \\
\hline Physiological PI & 15 & 52 & 31 & 62 & 38 & 100 & 86 \\
\hline Agronomic PI & 18 & 100 & 52 & 100 & 74 & 100 & 100 \\
\hline Reduction division & 19 & 67 & 60 & 100 & 78 & 100 & 100 \\
\hline Flowering/Anthesis & 22 & 100 & 74 & 100 & 87 & 100 & 100 \\
\hline Ripening & 18 & 18 & 0 & 14 & 0 & 26 & 15 \\
\hline
\end{tabular}
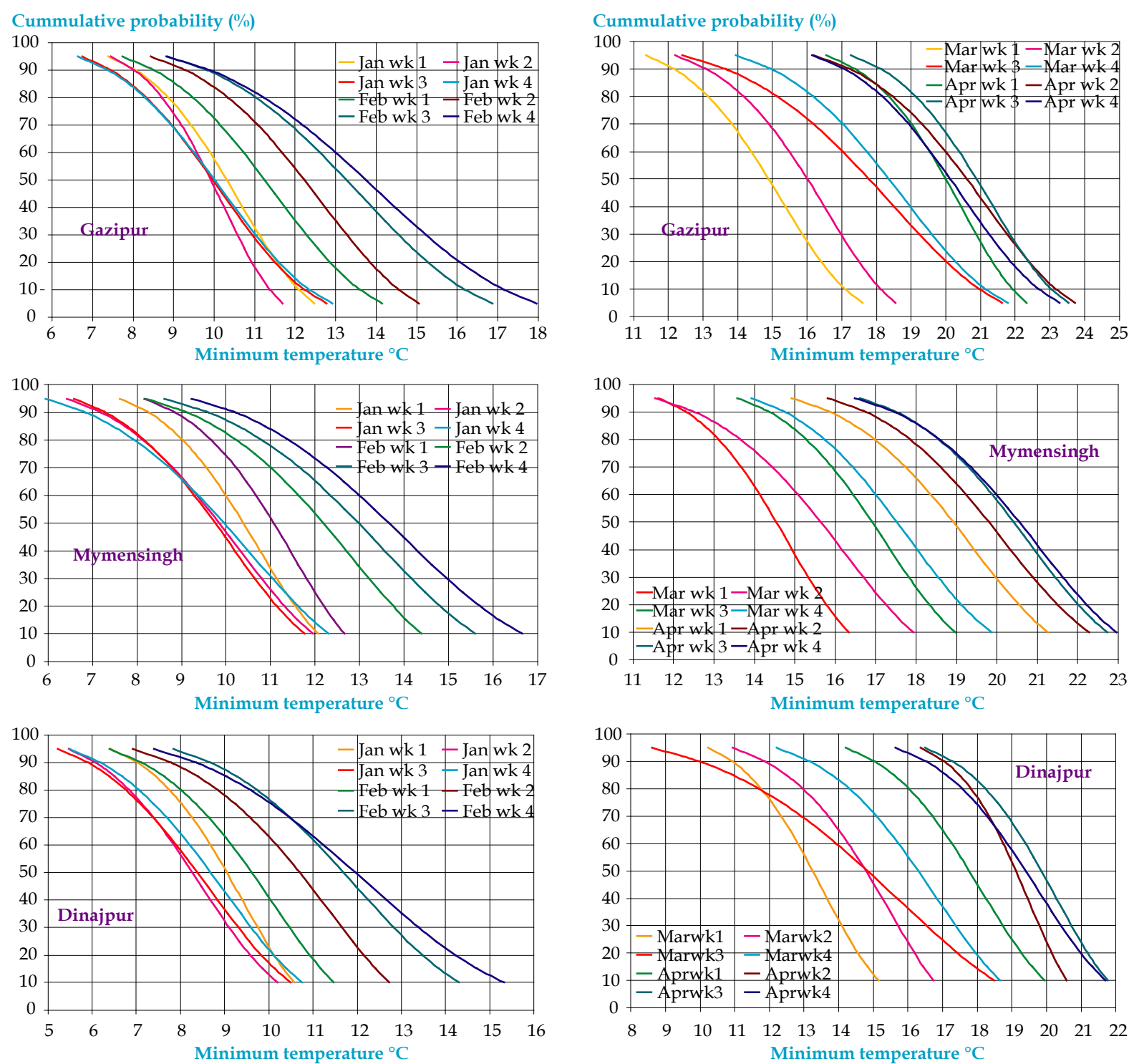

Fig. 3. Probability of minimum temperature occurred from January to April at Gazipur, Mymensingh and Dinajpur. 


\section{DISCUSSIONS}

From the above result it is obvious that irrespective of growth duration, the 1November established crop has more probability of getting cool-shock. However, 30November established crop has also some probabilities of experiencing critical low temperature too. This probability is remarkable for a short duration crop. That means, in Boro season a crop has some probabilities of encountering critical low temperature at any of the sensitive stages of the crop. Anyway, the cool-injury problem does not occur always. It depends on the duration of critical low temperature and diurnal change. When a rice plant is subjected to low temperature for three days, it is more sensitive at the booting (6-days prior to heading/flowering) than at heading as indicated by the higher percentage of sterility.

When the low temperatures are continued for 6-9 days, heading is equally or more sensitive than booting, Yoshida (1981). A rice plant subjected to temperature below $20^{\circ} \mathrm{C}$ at about RD (pre-booting stage) usually induced high spikelet sterility, Satake (1969; 1976). Temperature as low as $12^{\circ} \mathrm{C}$ would not induce sterility if they last for two days but would induce about $100 \%$ if they last for six days.

Generally, low temperature mediated sterility is attributed to night temperature and high to the day (high temperature). The high temperature during cool period has the ability to alleviate the effects of low night temperature, Yoshida (1981). There is the probability of low critical temperature $\left(<15^{\circ} \mathrm{C}\right)$ during $1^{\text {st }}$ week of March at the API of short duration Boro crop. A relatively early established long duration crop might experience the similar fate. When a crop is established early (1-November), API, RD stages of a short duration crop have to suffer from critical low temperature of $10-14^{\circ} \mathrm{C}$ during early to mid February (Table 3).

The level of high temperature during the same period was $27-29^{\circ} \mathrm{C}$. In contrast, long duration crop established on 1 November has to experience the critical low temperature of 15$16^{\circ} \mathrm{C}$ for the same growth stages. But the high temperature for the same period is $32^{\circ} \mathrm{C}$. There is a $4-5^{\circ} \mathrm{C}$ variation of critical low temperature and high temperature for the growth stages here. So not only the variation of high temperature but also the variation of critical low temperature might have some role in the alleviating effect of cool-injury. Similar results were observed by Gomostaet al. (2001). They observed that short duration BRRI dhan 28 have $64.6 \%$ sterility to yield $2.5 \mathrm{t} / \mathrm{ha}$ and BRRI dhan 29 have $40.8 \%$ sterility to yield $6.5 \mathrm{t} / \mathrm{ha}$ when seeded on early November. The above mentioned late established short and long duration varieties have $35.9 \%$ and $32.8 \%$ sterility and 6.8 and $7.5 \mathrm{t} / \mathrm{ha}$, grain yield respectively (Table 4 ). 
Table 3. Distribution of weekly temperature in Dinajpur, Mymensingh and Gazipur at $\mathbf{8 0 \%}$ probability

\begin{tabular}{|c|c|c|c|c|c|c|}
\hline \multirow{3}{*}{ Week } & \multicolumn{6}{|c|}{ Temperature $\left({ }^{\circ} \mathrm{C}\right)$} \\
\hline & \multicolumn{2}{|c|}{ Gazipur } & \multicolumn{2}{|c|}{ Mymensingh } & \multicolumn{2}{|c|}{ Dinajpur } \\
\hline & Min. & Max. & Min. & Max. & Min. & Max. \\
\hline NovWk1 & 17.99 & 31.49 & 20.81 & 32.40 & 19.04 & 32.04 \\
\hline NovWk2 & 16.28 & 30.45 & 19.24 & 31.96 & 17.44 & 31.29 \\
\hline NovWk3 & 14.79 & 29.56 & 17.86 & 31.28 & 16.24 & 30.68 \\
\hline NovWk4 & 13.41 & 28.93 & 16.46 & 30.69 & 14.06 & 29.98 \\
\hline DecWk1 & 12.22 & 27.66 & 15.21 & 30.28 & 13.27 & 29.11 \\
\hline DecWk2 & 11.37 & 27.18 & 14.29 & 29.18 & 12.82 & 28.31 \\
\hline DecWk3 & 10.27 & 26.24 & 12.01 & 28.43 & 9.98 & 27.57 \\
\hline DecWk4 & 9.57 & 26.21 & 11.78 & 28.52 & 9.98 & 27.37 \\
\hline JanWk1 & 8.87 & 24.79 & 11.56 & 27.54 & 10.12 & 27.29 \\
\hline JanWk2 & 8.71 & 24.77 & 11.31 & 27.30 & 9.58 & 26.61 \\
\hline JanWk3 & 8.32 & 25.77 & 11.14 & 27.33 & 9.83 & 27.96 \\
\hline JanWk4 & 8.29 & 26.54 & 11.62 & 28.23 & 10.11 & 27.9 \\
\hline FebWk1 & 9.47 & 27.35 & 12.2 & 28.99 & 10.93 & 28.41 \\
\hline FebWk2 & 10.34 & 28.09 & 13.76 & 30.35 & 12.15 & 30.23 \\
\hline FebWk3 & 11.03 & 29.51 & 14.81 & 31.95 & 13.48 & 31.03 \\
\hline FebWk4 & 11.22 & 29.69 & 15.71 & 32.13 & 14.23 & 32.23 \\
\hline MarWk1 & 13.15 & 30.98 & 15.78 & 33.60 & 14.55 & 32.97 \\
\hline MarWk2 & 14.17 & 32.20 & 17.26 & 34.71 & 16.19 & 34.68 \\
\hline MarWk3 & 15.14 & 33.13 & 18.33 & 35.72 & 17.43 & 35.54 \\
\hline MarWk4 & 16.18 & 33.85 & 19.12 & 36.23 & 17.96 & 37.21 \\
\hline Aprwk1 & 18.36 & 33.97 & 20.55 & 36.86 & 19.28 & 38.17 \\
\hline Aprwk2 & 18.47 & 33.95 & 21.5 & 37.06 & 20.15 & 38.37 \\
\hline Aprwk3 & 19.13 & 33.66 & 22.01 & 37.18 & 21.19 & 38.84 \\
\hline Aprwk4 & 18.17 & 33.92 & 22.22 & 36.91 & 20.99 & 37.73 \\
\hline
\end{tabular}

Table 4. Effect of seeding time on sterility, grains $\mathrm{m}^{-2}$ and grain yield (Gomostaet al., 2001)

\begin{tabular}{l|c|c|c|c|c|c}
\hline \multirow{2}{*}{ Seeding date } & \multicolumn{2}{|c|}{ Sterility (\%) } & \multicolumn{2}{c|}{ Grains $^{-2}$} & \multicolumn{2}{c}{ Grain yield (t/ha) } \\
\cline { 2 - 7 } & $\begin{array}{c}\text { BRRI } \\
\text { dhan28 }\end{array}$ & $\begin{array}{c}\text { BRRI } \\
\text { dhan29 }\end{array}$ & $\begin{array}{c}\text { BRRI } \\
\text { dhan28 }\end{array}$ & $\begin{array}{c}\text { BRRI } \\
\text { dhan29 }\end{array}$ & $\begin{array}{c}\text { BRRI } \\
\text { dhan28 }\end{array}$ & $\begin{array}{c}\text { BRRI } \\
\text { dhan29 }\end{array}$ \\
\hline 1 November & 64.6 & 40.8 & 16456 & 20536 & 2.5 & 6.5 \\
30 November & 35.9 & 32.8 & 22602 & 25282 & 6.8 & 7.5 \\
\hline
\end{tabular}

The early established short duration variety, in this case encounter low temperature stress during the reproductive phase resulted more sterility and poor yield as well. In contrast, the early established long duration variety experienced low temperature stress at vegetative phase prolonging the growth duration and attained enough scope to avoid low temperature stress at the reproductive phase. Irrespective of variety, the late established crop had enough opportunity to compensate the low temperature through the alleviating effect of high temperature during the reproductive phase resulting comparatively low sterility and higher yield.
For haor area, short duration variety is advocated to cultivate to avoid flash flood provided the establishment must not be too early. Even the early crop could be advocated provided the crop should have long growth duration. However, the early established long duration crop has elongated vegetative phase. Early transplanting dates ensure safety from flood damage but the opportunity for manipulating seedling age is limited because of low temperature, Salam et al. (1994). The late established crop is good for avoidance of low temperature at the reproductive phase but probability to encounter flashflood is very high, Biswaset al. (2008). Even the crop might encounter high temperature stress at the 
flowering/anthesis. The high temperature during last April to May goes beyond $35^{\circ} \mathrm{C}$, a critical level of high temperature injury. If the anthesis and the critical temperature coincide anyway, a severe sterility might occur.

Another important consideration is the return period of the critical low temperature. It is observed that the temperature $<15^{\circ} \mathrm{C}$ occurs in every year during 3rd and 4th week of February at Gazipur, Mymensingh and Dinajpur but $15-20^{\circ} \mathrm{C}$ temperature occurs once in every five and three years in Gazipur, 10 and five years in Mymensingh during 3rd and 4th weeks of February, respectively (Table 5).

The similar pattern of temperature is observed in Dinajpur only at the 4th week of February. In Gazipur and Mymensingh, $10-15^{\circ} \mathrm{C}$ and 15- $20^{\circ} \mathrm{C}$ temperature occurs in every alternate year in the 1st and 2nd weeks of March. The similar frequency occurs in Dinajpur but in the 2nd and 3rd weeks of March. In Dinajpur, $10-15^{\circ} \mathrm{C}$ occurs in every year but $15-20^{\circ} \mathrm{C}$ occurs once in every 20 years in the 1st week of March. In the 3 rd and 4th weeks of March, $15-20^{\circ} \mathrm{C}$ occurs in every year in both Gazipur and Mymensingh but $10-15^{\circ} \mathrm{C}$ occurs once in every five and seven years in Gazipur and seven and 10 years in Mymensingh, respectively. During 4th week of March $15-20^{\circ} \mathrm{C}$ occurs in every year but $10-15^{\circ} \mathrm{C}$ occurs once in every four years in Dinajpur. Therefore, periodic return of critical temperature with respect to growing region should be a consideration for planning a Boro crop.

Table 5. Return period of occurring cold temperature

\begin{tabular}{|c|c|c|c|c|c|c|c|c|c|c|c|c|}
\hline \multirow{2}{*}{ Week } & \multicolumn{4}{|c|}{ Gazipur } & \multicolumn{4}{|c|}{ Mymensingh } & \multicolumn{4}{|c|}{ Dinajpur } \\
\hline & $<10$ & $10-15$ & $15-20$ & $20-25$ & $<10$ & $10-15$ & $15-20$ & $20-25$ & $<10$ & $10-15$ & $15-20$ & $20-25$ \\
\hline DecWk1 & & 1.25 & 5.00 & & & 1.33 & 6.67 & & 10.00 & 1.25 & & \\
\hline DecWk2 & 10.00 & 1.18 & 20.00 & & & 1.11 & & & 10.00 & 1.25 & & \\
\hline DecWk3 & 5.00 & 1.25 & & & & & 2.50 & 2.00 & 1.25 & 10.00 & & \\
\hline DecWk4 & 3.33 & 1.43 & & & 4.0 & 1.54 & & & 1.25 & 10.00 & & \\
\hline JanWk1 & 2.22 & 1.82 & & & 2.9 & 1.82 & & & 1.33 & 6.67 & & \\
\hline JanWk2 & 1.82 & 2.22 & & & 2.0 & 2.50 & & & 1.18 & 20.00 & & \\
\hline JanWk3 & 1.82 & 2.22 & & & 1.8 & 2.86 & & & 1.25 & 10.00 & & \\
\hline JanWk4 & 2.00 & 2.00 & & & 2.0 & 2.50 & & & 1.33 & 6.67 & & \\
\hline FebWk1 & 3.33 & 1.43 & & & 4.0 & 1.54 & & & 1.82 & 2.86 & & \\
\hline FebWk2 & 5.00 & 1.25 & & & 6.7 & 1.33 & & & 2.86 & 1.82 & & \\
\hline FebWk3 & 10.00 & 1.43 & 5.00 & & 10.0 & 1.43 & 10.00 & & 5.00 & 1.43 & & \\
\hline FebWk4 & 10.00 & 1.67 & 3.33 & & 20.0 & 1.54 & 5.00 & & 5.00 & 1.54 & 20.00 & \\
\hline MarWk1 & & 1.82 & 2.22 & & & 1.67 & 3.33 & & & 1.18 & 20.00 & \\
\hline MarWk2 & & 2.86 & 1.54 & & & 2.86 & 1.82 & & & 2.00 & 2.50 & \\
\hline MarWk3 & & 5.00 & 1.67 & 5.00 & & 6.67 & 1.33 & & & 2.50 & 2.50 & \\
\hline MarWk4 & & 6.67 & 1.54 & 5.00 & & 10.00 & 1.25 & & & 4.00 & 1.54 & \\
\hline Aprwk1 & & & 1.82 & 2.22 & & 20.00 & 1.54 & 5.00 & & 20.00 & 1.18 & \\
\hline Aprwk2 & & & 2.22 & 1.82 & & & 2.00 & 2.50 & & & 1.33 & 6.67 \\
\hline Aprwk3 & & & 2.86 & 1.54 & & & 2.50 & 2.00 & & & 2.00 & 2.50 \\
\hline Aprwk4 & & & 2.00 & 2.00 & & & 2.50 & 2.00 & & & 1.67 & 3.33 \\
\hline
\end{tabular}

\section{CONCLUSIONS}

The probability of low temperature occurrence from the crop establishment to the flowering stage is a great concern. The probability of experiencing stage-wise critical temperature approaches to $100 \%$ for early established and short duration crop. However, the late established and long duration crop has the probability little less than the early and short duration crop. Irrespective of growth duration, the yield is affected a little of the late established crop. Despite low temperature along with the reproductive phase, the late established crop is quite safe due to the parallel high (day) temperature $\left(31-35^{\circ} \mathrm{C}\right)$. The high 
temperature appears to play an important role through the alleviating effect of low temperature. But early-established particularly short duration variety could not escape the low temperature at some of its important growth stages as the high temperature appears to stay a several degree low $\left(27-29^{\circ} \mathrm{C}\right)$ at that time. The low level of high temperature is appeared to drag down the low temperature to aggravate the growth and development of a crop. Therefore, not only the variation of high temperature of the day but also the variation of critical low temperature might have some role in the alleviating effect of cool-injury. Therefore, the critical low temperature, the high temperature during the low temperature period, periodic return of the critical low temperature with respect to growing region and concerned factors should be a consideration for planning a Boro crop. However, the influence of high temperature with respect to the low temperature deserves further study.

\section{REFERENCES}

Biswas, J. K., M. S. Hossain, M. S. I. Mamin and M. A. Muttaleb. 2008. Manipulation of seeding date and seedling age to avoid flash flood damage of Boro rice at the northeastern haor areas in Bangladesh. Bangladesh Rice J., 13 (1), 57-61.

Gomosta, A R, H A Quayyum, and A AMahboob. 2001. Tillering duration and yielding ability of rice varieties in the winter rice season of Bangladesh, In:Peng, S and B. Hardy: Rice Research for Food Security and Poverty Alleviation. Proceeddings of international Rice Research Conference, 31 March 3 April 2000. Loss Banoss, Philippines, IRRI, 692 p.

Howlader, M . 2007. Modeling probability distribution of weather variables and characterization of rainfed rice growing environment in Bangladesh. $\mathrm{PhD}$ thesis, July 2007, Jahangirnagar University, Savar, Dhaka, Bangladesh.

Hoshikawa, K., C F Yoshida, 1981. Growth of rice plant.Nosan-gyoson-Bunka-Kyokai, Tokyo. 317p.

Nishiyama., T. Matsuo, K. Kumazawa, R. Ishii, K. Ishihara and H. Hirata 1995. Damage due extreme temperatures.Science of Rice Plant, Food and Agriculture Policy Research Center, Tokyo. II, 769812.

Salam, M U, P R Street and J G W Jones. 1994. Potential production of Bororice in the haorregion of Bangladesh: Part3. Agricultural-systems. 46 (3), 295310.

Satake, T. 1969. Research on cool injury of paddy rice plant in Japan. JARQ 4(4), 5-10.

Satake, T. 1976. Sterile type cool injury in paddy rice plants. Climate and Rice, IRRI, Los Banos, Philippines, 281-300. 